Review

\title{
The Thermodynamically Expensive Contribution Of Three Cal- cium Sources To Somatic Release Of Serotonin
}

\author{
Francisco F. De-Miguel
}

Instituto de Fisiología Celular-Neurociencias, Universidad Nacional Autónoma de México. Circuito Exterior, Ciudad Universitaria, 04510, D. F., México.

E-mail: ffernand@ifc.unam.mx

\begin{abstract}
The soma, dendrites and axon of neurons may display calcium-dependent release of transmitters and peptides. Such release is named extrasynaptic for occurring in the absence of synaptic structures. This review describes cooperative actions of three calcium sources on somatic exocytosis. Emphasis is given to the release of serotonin by the classical serotonergic leech Retzius neuron, which has allowed detailed studies of each step between excitation and exoctytosis. Trains of action potentials induce transmembrane calcium entry through L-type channels. If the frequency of action potentials is above $5 \mathrm{~Hz}$, summation of calcium transients upon individual action potentials increases the intracellular calcium concentration to activate calcium-induced calcium release. The amplified calcium wave activates motochondrial ATP synthesis that fuels the transport of vesicles to the plasma membrane. Serotonin that is released activates autoreceptors coupled to phospholipase C. Production of IP3 produces release of calcium that sustains the large-scale exocytosis. The swiss-clock workings of the release machinery for somatic exocytosis has a striking disadvantage. The essential calcium-releasing endoplasmic reticulum that lays between resting vesicles and the plasma membrane becomes an obstacle for the vesicle transport. Such architecture reduces drastically the thermodynamic efficiency of the vesicle transport and elevates its energy cost.
\end{abstract}

Keywords: Calcium channels; somatic exocytosis; serotonin; extrasynaptic release; leech

\section{EXTRASYNAPTIC EXOCYTOSIS OF TRANSMITTERS AND PEPTIDES}

Streams of action potentials or long depolariztions may evoke calcium-dependent exocytosis of transmitters and peptides from the soma, dendrites and axon of neurons in the absence of pre- and postsynaptic structures.1-6 In contrast to the fast and localized release from synapses, extrasynaptic release is slow and difuse, producing effects by means of volume condiction of signalling substances.7 Synaptic release contributes to rapid communication by neuronal circuits. By contrast, substances that are released extrasynaptically reach targets at variable distances to modulate the workings of populations of neurons, but also glia and blood vessels.8,9 The effects of extrasynaptic exocytosis are out of the scope of this review. However, extensive reviews can be found in the literature.10-17

All peptides and most classical low molecular weigth transmitters have been shown to be released extrasynapticaly. 6 Release occurs from vesicles, either clear but ofter densecore vesicles that often rest distantly from the plasma membrane. Therefore, vesicles must mobilize to the plasma membrane on electrical activity and calcium entry.18,19 Calcium is not only essential for vesicle fusion, but has intermediate roles on vesicle transport. This review will summarize experimental data about the ways by which calcium flows through transmembrane and intracellular channels contribute in an orderly manner to induce vesicle transport and exocytosis. The backbone for the paper are experiments made in the soma of the classical large serotonergic Retzius neuron of the leech CNS, which allows 
direct experimentaiton to resolve the fine steps that couple electrical activity with the large-scale exocytosis.16 Stimuation of Retzius neurons in an isolated ganglion with trains of impulses that evoke massive serotonin release, activate after a few minutes the crawling circuit.20 Additional data from different types of neurons will be mentioned along the text.

\section{THREE CALCIUM SOURCES COOPERATE TO SOMATIC EXOCYTOSIS}

Calcium ions play three sequential and complementary roles on somatic exocytosis of transmitters an peptides. The first two calcium sources cooperate to induce the transport of vesicles. The third source catalizes vesicle fusion.

The electron micrographs in Figure 3 show the effects of electrical stimulation and calcium entry on somatic clusters of serotonin containing dense core vesicles in Retzius neurons. Electrical stimulation with $1 \mathrm{~Hz}$ trains, a frequency similar to the spontaneous firing frequency of serotonergic and in general in monoaminergic neurons21-24, fails to promote any vesicle mobilization to the plasma membrane and exocytosis. Increasing the frequency of the train of $20 \mathrm{~Hz}$ produces $~ 50 \%$ of the vesicle clusters in electron micrographs to appear closely apposed of the plasma membrane.25 If a similar stimulation pattern is delivered in the presence of extracellular horseradish peroxidase, gold-coupled anti-peroxidase antibodies find peroxidase inside vesicles, indicating that those vesicles underwent exo-endocytosis.26 In the presence of magnesium substituting for calcium, vesicles remain at resting positions after $20 \mathrm{~Hz}$ stimulation.27

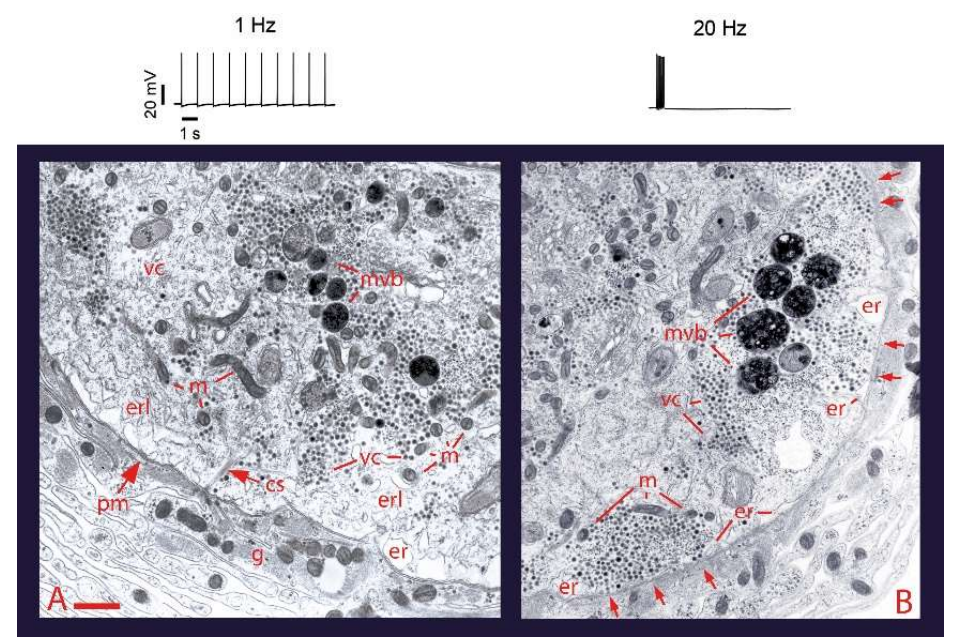

Figure 1. Calcium entry on electrical activity promotes vesicle transport to the plasma membrane. A. Electron micrograph of a soma fixed after $1 \mathrm{~Hz}$ stimulation (train on top). Vesicles remain distant from the plasma membrane. B. After $20 \mathrm{~Hz}$ stimulation (top) vesicle clusters appear apposed to the plasma membrane (arrows). $\mathrm{vc}=$ vesicle clusters; $\mathrm{mt}=$ microtubules; pm=plasma membrane; $\mathrm{m}=$ mitochondria; er=endoplasmic reticulum; $\mathrm{mvb}=$ multivesicular bodies; $\mathrm{g}=$ glial cell processes. Scale bar $=1 \mu \mathrm{m}$. From reference 19 . .

\section{CALCIUM ENTRY TRHOUGH L-TYPE CHANNELS IN THE NEURONAL SOMA}

The first source of calcium in the process of somatic exocytosis in Retzius neurons is the transmembrane flow through L-type (CaV1) channlels.28, 29 L-type channels are well suited for responding to sustained electrical activity, such as the $20 \mathrm{~Hz}$ trains that maximize somatic exocytosis in Retzius neurons and in other serotonergic and peptidergic neurons,30-31 since their slow or lack of inactivation permits continuous calcium flow during large depolarizations of trains of action potentials by neurons. La type channels 
contribute to somatic release in retinal dopaminergic neurons 3 and in serotonergic neuroepithelial cells.32 In dendrites of magnocellular neurons and other cell types $\mathrm{N}$ type channels (CaV2.2) contribute to somatodendritic exocytosis alone or in collaboration with L-type channels.33, 34 However, the inactivation of N-type channels restrict their frequency-responses over long periods of electrical activity. In dendirtes of magnocellular neurons, serotonergic rafe neurons and dopamine ganglion neurons calcium elevations may result from activation of glutamate receptors, usually in absence of local action potentials.3, 35-36

Evidence about the presence of L-type channels in the plasma membrane of the soma of Retzius neurons came first from loose patch clamp recordings of currents from small areas of the plasma membrane. Figure 2 shows that calcium tail currents in the soma are smaller thant those in the axon stump, a preferetial region for regeneration of neurites and synapse formation in culture.37 The kinetics of the activation of somatic calcium currents was reconstructed from the superposition of isolated calcium tail currents recorded from a patch of memebrane in response to increasingly larger depolariztion pulses. As shown in Figure $3 b$, the calcium current lacks inactivation, as expected for L-tye currents but not for calcium currents carried by other types of calcium channels.

A

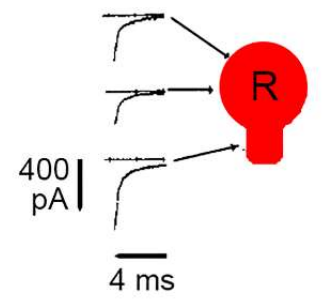

B

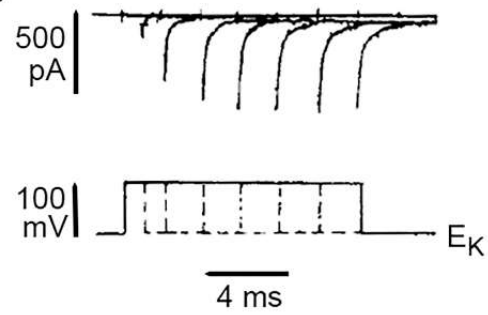

Figure 2. Direct recordings of L-type channels from the soma membrane. A. Loose patch clamp recordings of calcium tail currents from small patches of membrane upon 10 ms depolarization. B. Lack of inactivation of somatic calcium current indicating activation of L-type calcium channels. The kinetics of activation were reconstructed from superimposition of loose patch records of tail currents after depolarizations with increasing durations. Potassium tail currents were prevented by clamping the voltage at the potassium equilibrium potential. Sodium tail currents were eliminated by reducing the extracellular sodium concentration. From reference 37.

\section{HIGH-FREQUENCY ACTIVATION OF L-TYPE CHANNELS PROMOTES SOMATIC EXOCYTOSIS}

Somatic exocytosis of serotonin can be evoked in Retzius cells by trains of of action potentials but not by individual action potentials.28 Trains of ten impulses evoke exocytosis that can be conveniently visualized from the formation of spots of FM1-43 fluorescent dye near the plasma membrane. Each spot forms upon accumulation of dye inside vesicles in a cluster as they undergo exo-endocytosis cycles. Therefore, each sport refflects the arrival and fusion of a whole cluster of vesicles. Although stmulation at $1 \mathrm{~Hz}$ fails to evoke exocytosis, a number of fluorescent spots are produced by constitutive expcytosis in the absence of stimulation, on $1 \mathrm{~Hz}$ stimulation or on $20 \mathrm{~Hz}$ stimulation in experimental conditions that eliminate calcum entry.27 Above $5 \mathrm{~Hz}$, the number of fluorescent spots increases with the stimulation frequency. A plateau at $20 \mathrm{~Hz}$ is reached in these and in other neuron types,29-31 suggesting a máximum efficienty for calcium entry. For the reasons above, stimulation with 1 or $20 \mathrm{~Hz}$ trains has been succesfully used in combination with different experimental manipulations to analyze the mechanism of somatic exocytosis. 
Figure 3. Somatic exocytosis as measured from FM1-43 fluorescence staining. A. Stimulation with
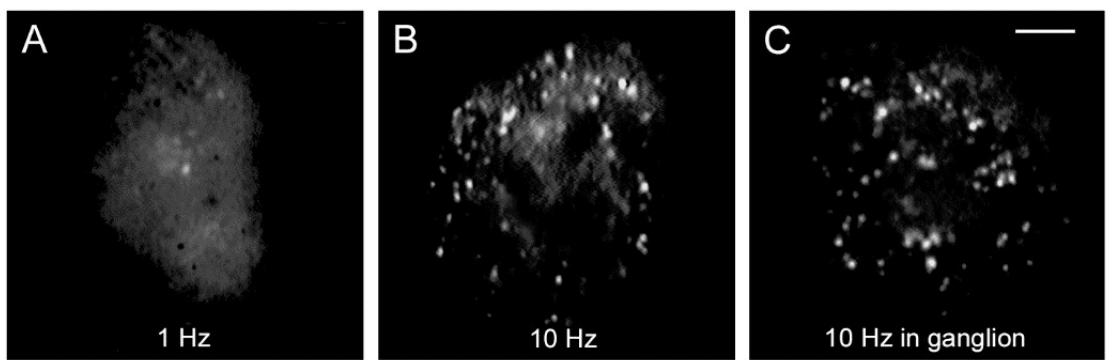

a $1 \mathrm{~Hz}$ train produces small numbers of fluorescent spots in the soma of cultured neurons. Each spot is a release site in which multiple dense core vesicles fuse. B. Increase in the nubmer of spots after a $10 \mathrm{~Hz}$ train. C. Similar staining in the soma of a neuron stimulated in the ganglion. Obtained with permission from reference 28 .

Blockade of L-type channels by incubation of cultured neurons with nimodipine abolishes exocytosis upon a $20 \mathrm{~Hz}$ train, without affecting constitutive exocytosis (Figure $4 \mathrm{~A})$. Subsequent addition of caffeine to the same neurons as a way to release large amounts of calcium from the smooth endoplasmic reticulum in absence of electrical stimulation, produced a new bulk of exocytosis, as seen by the increase in the number of fluorescent spots in Figure 4B. Such results clarified that calcium entry upon activation of $\mathrm{L}$ type channels promotes both, the vesicle transport and exocytosis.
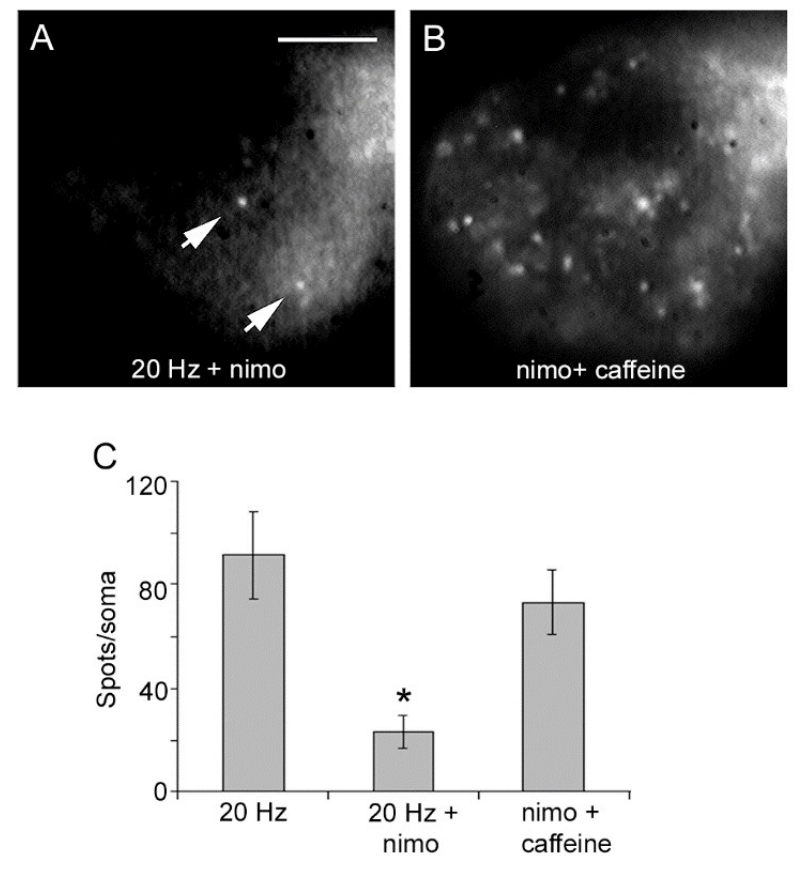

Figure 4. Blockade of L-type channels abolished somatic exocytosis. A. Incubation with nimodipine (nimo) abolishes exocytosis upon a $20 \mathrm{~Hz}$ stimulation train, as quantified from the formation of FM1-43 fluorescent spots. The spots pointed by the arrow remained in B. B. Caffeine in the presence of nimodipine succeeded to evoke vesicle transport and exocytosis in absence of electrical stimulation. E. Quantitation of exocytosis (fluorescent spots per soma) in each experimental condition. The images show selected areas of the soma. The bars are the S.E.M.; the asterisk indicates $\mathrm{P}>0.05 \mathrm{~T}$ test significance. Obtained with permission from reference 28. 


\section{ANALYSIS OF THE CALCIUM DYNAMICS}

The dynamics and pharmacology of the calcium signals that control exocytosis was analyzed in detail from the fluorescence of the high affinity Fluo 4 or 5 calcium sensors. An observation from such measurements was that calcium transients on each individual action potential summed temporarily in a frequency-dependent manner. Figure 5 superimposes the calcium kinetics in response to $1 \mathrm{~Hz}$ and $20 \mathrm{~Hz}$ trains. Whereas individual transients produced by each action potential at $1 \mathrm{~Hz}$ could be well-resolved, summation at $20 \mathrm{~Hz}$ frequency produced a rapid large monophasic wave with a peak by $600 \mathrm{~ms}$, followed by an exponential decay with a $\sim 3$ s time constant. A second observation was that the amplitude of the calcium signal on a train increased supra-linearly as the frequency was increased (Figure 5B and C), thus suggesting the recruitment of another source of calcium as the stimulation frequency increases. The remarkable difference between the peak and the integral of the calcium transient indicates that it is the concentration increase and not the total amount of calcium what determines the amount of exocytosis. 31

A

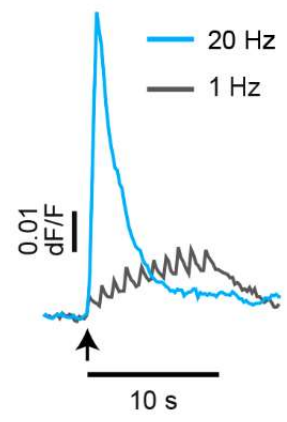

B

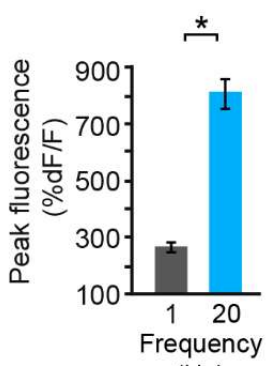

$(\mathrm{Hz})$

\section{C}

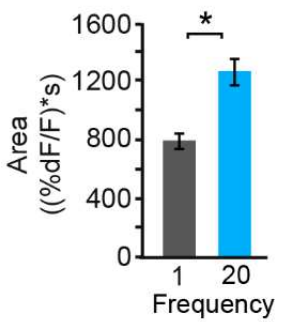

$(\mathrm{Hz})$

Figure 5. Frequency dependence of calcium signals. A. Calcium transients at the vicinity of the plasma membrane. B. Peak amplitude of the transients. C. Integral of the calcium transients. The supralinear summation of calcium upon $20 \mathrm{~Hz}$ stimulation seen from the difference between the amplitude and the integral of the transients suggest an additional calcium component. From reference 31 .

Figure 6 shows that the fast calcium transient produced by a $20 \mathrm{~Hz}$ train acted as a tsunami to invade the whole soma. Another originally unexpected observation, shown in Figure 6 is that the fast calcium transient is followed by a calcium transient occurring exclusively at the soma shell. Such transient persists for hundreds of seconds in the absence of any stimulation.

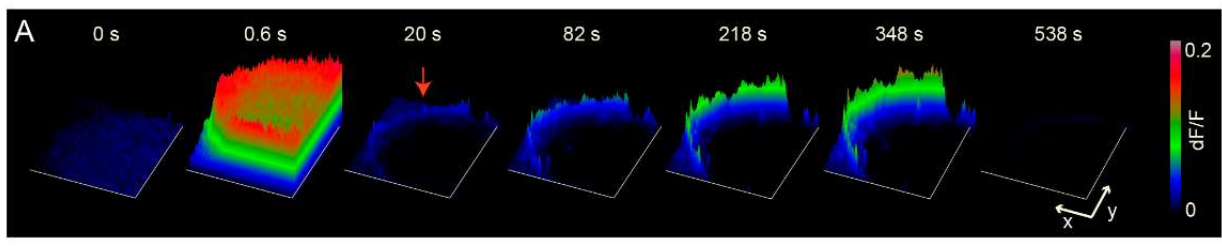

Figure 6. Calcium dynamics on $20 \mathrm{~Hz}$ stimulation. The time-lapse sequence of fluorescent images shows the fast calcium transient invading the soma followed by the persistent transient in the periphery. Stimulation occurred at time $=0$ s. The time after stimulation is indicated above. The color code is proportional to the calcium concentration seen as a normalized $(\mathrm{dF} / \mathrm{F})$ fluorescence increase of calcium sensor. From reference 31. 
THE FAST CALCIUM TRANSIENT DETERMINES THE AMOUNT OF RELEASE.

As expected, blockade of L-type channels with nimodipine nearly abolished the fast calcium transient on $20 \mathrm{~Hz}$ stimulation (Figure 7). A second source of calcium produces the supralinear increase in the amplitude of the fast calcium transient. Blockade of calcium-induced calcium release by incubation of neurons with a cocktail of ryanodine (to block ryanodine-sensitive intracellular calcium channels) and thapsigargin (to deplete the internal calcium pool in the endoplasmic reticulum), reduced the fast calcium transient by $\sim 40 \% 31$. Release of calcium from intracellular stores also contributes to dopamine somatodendritic release from nigrostriatal neurons 38 and to peptide release from magnocellular neurons.39 Such experiments allowed correlating the nature and the effects of the calcium tsunami on somatic release. Figure 7 shows that the amplitude of the fast calcium transient determined the amount of somatic fluorescent spots, therefore with the frequency dependence of release.

Such results indicate that the primary role of the calcium tsunami is to set in motion the transport of vesicle clusters to the plasma membrane. The calcium tsunami stimulates mitochondrial synthesis of ATP. The newly synthesized ATP provides the energy for kinesin-tubulin and actin myosin motor systems to carry vesicle clusters to the plasma membrane. 27 The transport takes place at $15-90 \mathrm{~nm} / \mathrm{sec}$ velocity, depending primarily on the vesicle cargo.19 The number of transported vesicle clusters depends on the stimulation frequency, and the transfer is the amplitude of the fast calcium tsunami invading the mitochondria. 27

A

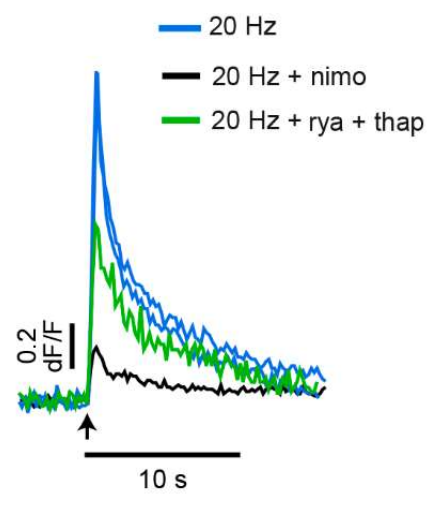

B

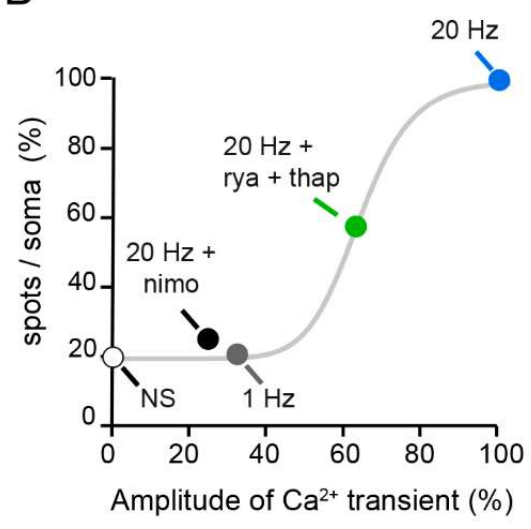

Figure 7. Calcium determinants on the amount of exocytosis. A. Kinetics of the fast calcium transient imaged from the vicinity of the plasma membrane. Application of L-type calcium blocker nimodipine reduces the transient by $80 \%$. Elimination of calcium-induced calcium release by combines ryanodine and thapsigargin reduce the transient by $40 \%$. B. The amplitude of the calcium transient determines the amount of release. The grey sigmoidal is the frequency-dependence on the amount of exocytosis. Constitutive exocytosis contributes with $\sim 20 \%$ of the spots per soma. NS= on stimulated. From reference 31 .

\section{EXOCYTOSIS IS SUSTAINED BY A POSITIVE FEEDBACK LOOP}

Comparing the kinetics of the calcium signals and exocytosis showed a striking result. The fast calcium tsunami finishes by the onset of exocytosis. Therefore, it triggers the vesicle transport and determines the amount of release, but does not contribute to the large-scale exocytosis. The calcium signal that maintains the large-scale exocytosis is the peripheral transient. 
The kinetics of exocytosis have been quantitatively analyzed from the kinetics of fluorescence increases in posts of FM dye. The lag to the onset of exocytosis reflects the distance and velocity of the vesicle cluster transport; the dynamic interval (a and a' in Figure 8) the rate of exocytosis, which is orders of magnitude faster than the vesicle transport, reflects the velocity of the transport; the plateau (c and $c^{\prime}$ in Figure 8) is reached at the end of exocytosis. By assuming that each vesicle fusion contributes equally to the fluorescence increase, the amplitude of the transient reflects how many vesicles fused.19 It is common that fusion of a vesicle cluster is followed by fusion of a second cluster at the same membrane spot, thus producing a second florescence increase ( $a^{\prime}$ and $c^{\prime}$ in Figure 8).

Simultaneous optical recordings of the kinetics of exocytosis and calcium from individual release sites indicate a two-way interaction between exocytosis and the peripheral calcium transient. Figure 8B shows that each FM fluorescence increase occurs in parallel to an increase in the peripheral calcium transient, and each plateau in the exocytosis kinetics correlates with a calcium peak ( $b$ and $b^{\prime}$ in Figure 8B). Moreover, each exocytosis plateau is followed by a reduction in the amplitude of the calcium transient. The cycles in the phase-state diagram in Figure 8C indicate a positive feedback loop between calcium and exocytosis.

A

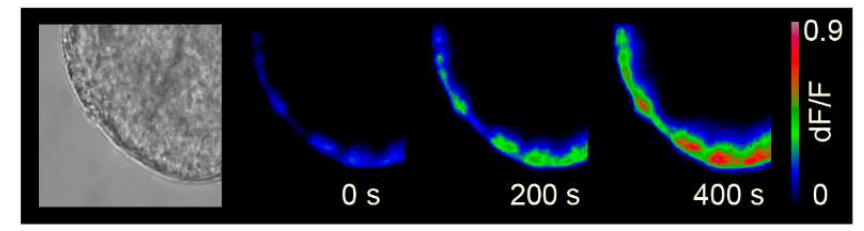

B

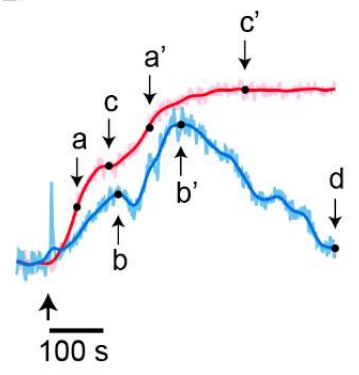

C

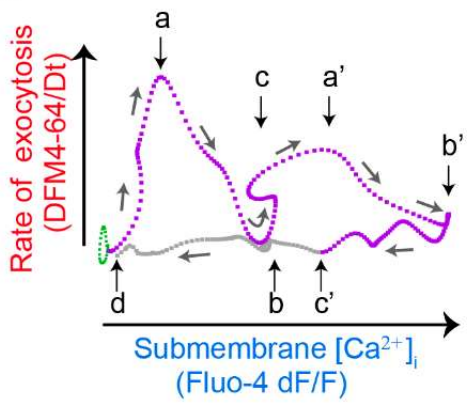

Figure 8. Exocytosis is maintained by a positive feedback loop. A. Slow development of FM4-64 dye fluorescent spots during exocytosis upon $20 \mathrm{~Hz}$ train. Images were taken from the equator of the soma in culture. B. Kinetics of exocytosis (red) and calcium (blue) from simultaneous optical recordings. Exocytosis displays two sigmoidal steps each corresponding to a vesicle cluster. a and a' are the dynamic ranges of exocytosis; $c$ and $c^{\prime}$ are the plateaus indicating the end of exocytosis from each vesicle cluster. In the calcium signal the spike synchronized to stimulation (arrow) is the fast calcium transient. Following is the peripheral transient with two elevations, each correlating with an exocytosis bulk. The peaks of the calcium signal and b' occur by the endo of exocytosis. The calcium levels return to rest when exocytosis finishes. C. State-phase diagram for the kinetics in C, indicating feedback loops established between calcium and exocytosis. Each cycle corresponds to exocytosis from one of the subsequent vesicle clusters. From reference 31.

\section{SEROTONIN THAT HAS BEEN RELEASED CONNECTS EXOCYTOSIS WITH CALCIUM}

The intracellular signals linking serotonin release to the liberation of intracellular calcium were found again by simultaneous optical recordings of the peripheral calcium signal and exocytosis in response to $20 \mathrm{~Hz}$ stimulation. Both signals were abolished by serotonin antagonist methisergide, which has higher specificity for type 2 receptors. The activated serotonin receptors and intracellular release of calcium are coupled by activation of phospholipase C (PLC) and production of IP3, since both exocytosis and the calcium 
elevation were abolished by application of PLC blocker U-73122. Therefore, the positive feedback loop that maintains the large-scale exocytosis of serotonin incorporates a four/step sequence: 1. Serotonin that has been released activates 5HT2 autoreceptors; 2. Activates serotonin receptors activate PLC followed by IP3 production. 3. IP3 activates IP3 receptor-channels producing calcium release from endoplasmic reticulum in neighboring plasma membrane. 4 . Calcium promotes exocytosis as vesicles arrive. The feedback loop gets to an end when the last vesicles in a cluster fuse, serotonin is removed from the extracellular space and calcium returns to resting levels.

\section{SEROTONIN ACTIVATES THE POSITIVE FEEDBACK LOOP FOR EXOCYTOSIS}

The calcium signal and exocytosis are coupled by serotonin that has been released, first as constitutive exocytosis; later as result of the arrival of vesicles at the plasma membrane. Figure 9A shows that application of serotonin with iontophoretic pipette to a spot of plasma membrane produces a peripheral calcium signal similar to that occurring during exocytosis. However, such calcium elevation is not enough to evoke exocytosis, most likely because it does not spread to the regions of resting vesicle-mitochondria to produce ATP for vesicle transport.
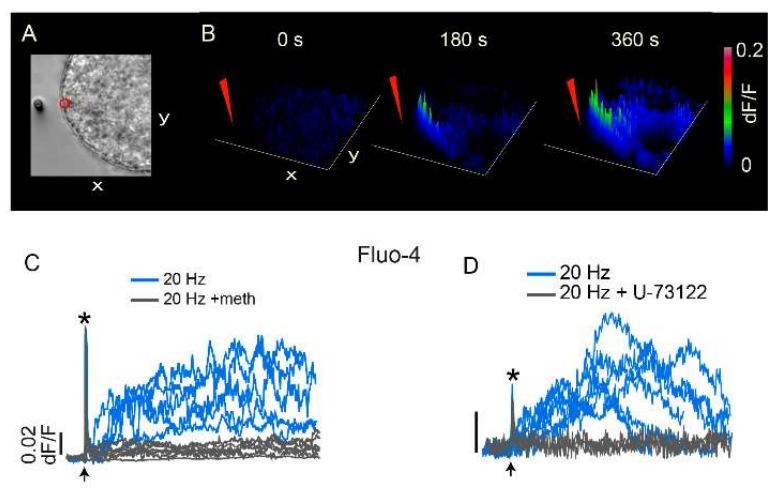

Fluo-4
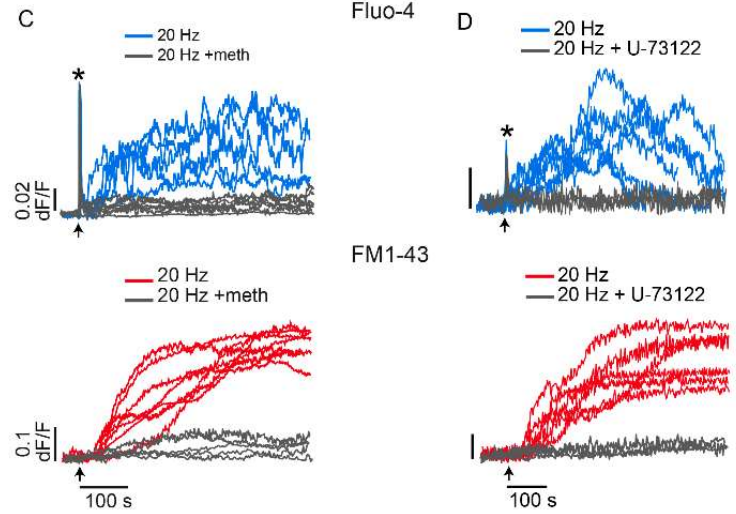

FM1-43

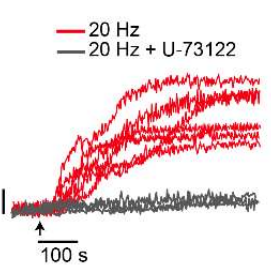

Figure 9. Activation of serotonin receptors and PLC are needed for the feedback loop. A. Soma of cultured neuron and the tip of pipette for iontophoretic serotonin application (left). The region from which calcium measurements were made is circled in red. B. Calcium elevations upon serotonin application in the neuron in A. C. Methisergide abolishes the peripheral calcium elevation (top left) and exocytosis (bottom left). D. The PLC blocker U-73122 abolishes calcium elevations (top right) and exocytosis (bottom right). Adapted from reference 31.

The mechanism for extrasynaptic exocytosis of serotonin is resumed in Figure 10. Such mechanism has more general relevance, since similar feedback loops maintain largescale somatodendritic exocytosis of peptides by magnocellular hypothalamic neurons 40 and by dorsal root ganglion neurons.41 
Calcium release from the endoplasmic reticulum is not in close proximity to the vesicles, as it is at synapses.42-46 Such mismatch requires the inefficient intracellular calcium diffusion to reach vesicles, and vesicles to contain calcium sensors more sensitive than the synaptotagmins 1 or 2 of synapses (Sudhof 2013).46 For example, the calcium requirement for release of peptides from the soma of dorsal root ganglion neurons is a ten-fold lower than at synapses.47 An alternative has solution been found in the soma and dendrites of dopaminergic neurons. Specific antibodies have identified the presence of the highly sensitive isoforms of calcium sensor synaptotagmin 4 and 7.48-49
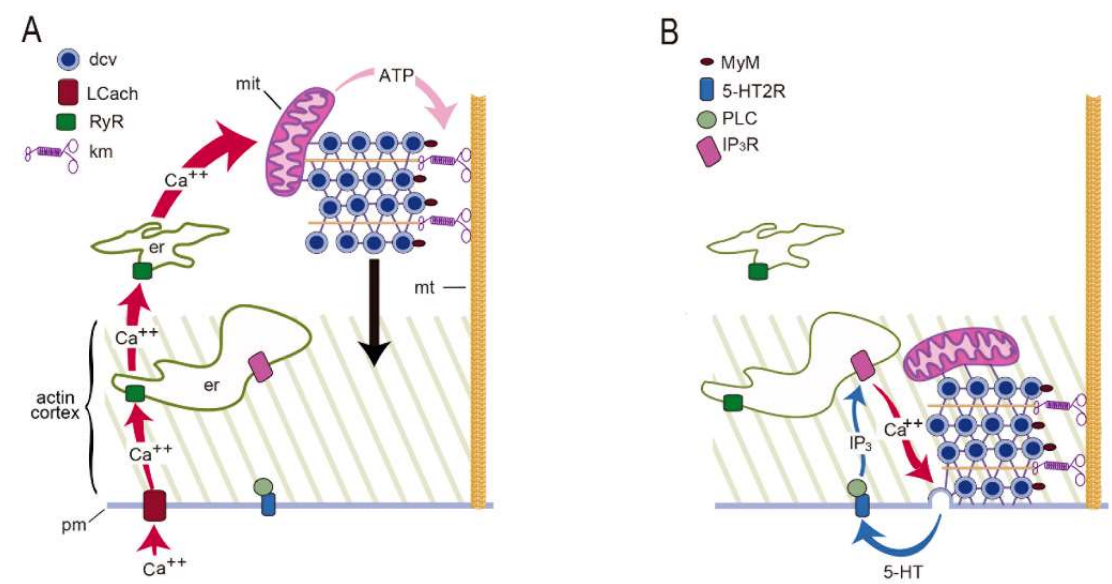

Figure 10. Mechanism for somatic exocytosis of serotonin. A. In response to a train of action potentials, L-type calcium channels (LCach) open. Calcium entry activates ryanodine receptors (RyR) in endoplasmic reticulum (er) to produce calcium-induced calcium release. The amplified calcium wave invades the soma. In the mitochondria (mit) calcium stimulates ATP synthesis. ATP activates kinesin motors $(\mathrm{km})$ that transport dense core vesocles ( $\mathrm{dcv}$ ) along microtubules $(\mathrm{mt})$. B. As vesicles enter the actin cortex, myosin motors (MyM) couple to actin and contribute to transport. Release is maintained by a positive feedback loop. Serotonin that is released activates 5-HT2 receptors (5HT2R). Activation of phospholipase C (PLC) produces IP3 which binds to receptors (IP3R) to activate intracellular calcium release. Such calcium maintains exocytosis going on until last vesicles fuse. From reference 16 .

\section{THE HIGH ENERGY COST OF THE USE OF THREE CALCIUM POOLS}

The Swiss clock precision of the machinery for somatic exocytosis imposes a high energy cost to the transport process. The amplified electron micrograph in Figure 11 shows details of the cytoarchitecture for somatic exocytosis. At rest or in neurons stimulated at $1 \mathrm{~Hz}$, vesicles are associated to microtubules that connect to the plasma membrane. The calcium-releasing endoplasmic reticulum, so necessary for the fast calcium tsunami and to maintain the large-scale exocytosis, rests on the vesicle pathway to the plasma membrane. Vesicle passage through such obstacles produces a high ATP energy cost from the friction forces. As result, there is a reduction in the thermodynamic efficiency of the ATP use. Figure 11B shows that after $20 \mathrm{~Hz}$ stimulation vesicles have made their way to the plasma membrane by displacing endoplasmic reticulum. 

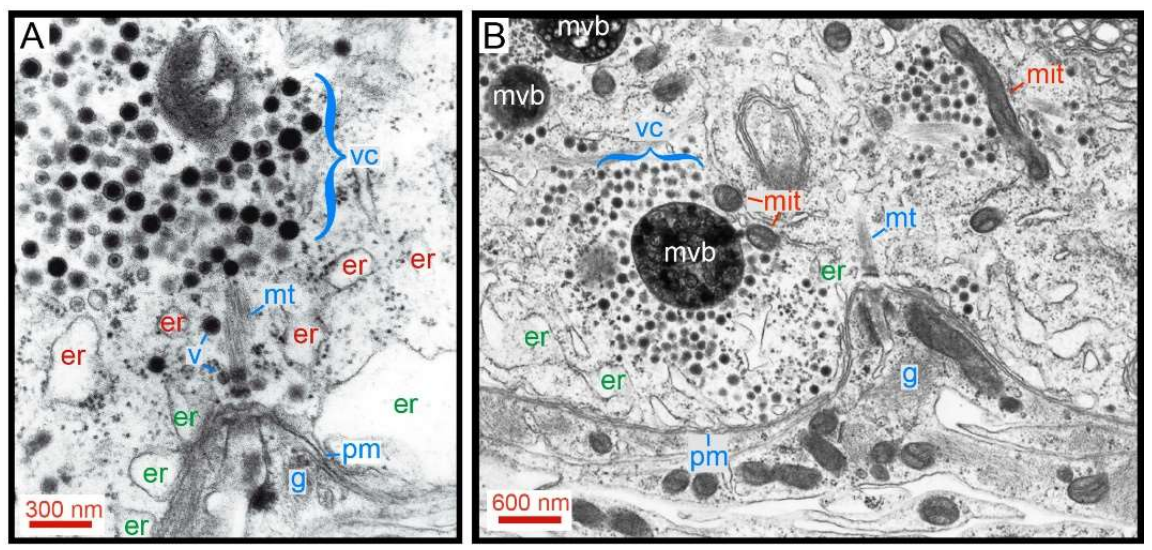

Figure 11. Cytoarchitecture of the vesicle transport pathway. A) Electron micrograph of a neuron fixed after $1 \mathrm{~Hz}$ stimulation. Somatic vesicle cluster (vc) at resting states are bound to the plasma membrane $(\mathrm{pm})$ though microtubules $(\mathrm{mt})$. Peripheral endoplasmic bags (er) rest apposed to the plasma membrane. A more internal layer of endoplasmic reticulum (er) contains smaller bags. Individual vesicles (v) from peripheral clusters approach the plasma membrane along microtubules. Glial cell processes (g) in an invagination of the Retzius neuron form an anchor site for microtubules. B) Electron micrograph of a release site in a neuron that had been stimulated with 20 $\mathrm{Hz}$ trains. Vesicles from a large cluster are apposed to the plasma membrane. Transport seemed pass through a bottleneck of endoplasmic reticulum. Mitochondria (mit) travel with vesicle clusters. Multi-vesicular bodies (mvb) form upon incorporation of vesicles after endocytosis. Note that exocytosis occurs onto the glia. From reference 50.

The ATP cost per vesicle and the thermodynamic efficiency of the vesicle transport have been calculated by applying thermodynamic theory to the kinetics of exocytosis, which as mentioned before expresses the number of vesicles in the cluster, their travelling distance and velocity (De-Miguel et al, 2012). Internal vesicle clusters (red in Figure 12) are mobilized by kinesin coupled to microtubules; distant vesicle clusters already inside the actin cortex use myosin carried within the clusters to assembly a second transport system upon coupling to the actin cortex.19, 50 It is remarkable that the vesicle clusters also carry the fuel-generator mitochondria all the way through (Figure 12B).

The barrier produced by the actin cortex for vesicle transport at rest turns into a permissive pathway in response to stimulation, an effect shown first in endocrine cells 51, 52 that appears repeatedly in neurons.53-55 Evidence principally from endocrine cells points to calcium as mediator of such transitions,56-57 although it has not yet been studied in relation to somatic exocytosis.

The ATP cost per vesicle estimated from thermodynamic theory applied to the vesicle transport and the thermodynamic efficiency of the ATP expenses are highly-dependent on the traveling distance of the vesicle.19, 50 The slopes of the curves in Figure 12 correlate well with the topology of the traveling pathway. The thermodynamic efficiency of the ATP expenses correlates with the resting position of vesicle clusters, their size and traveling velocity (Figure 12B.) Data allows to predict four groups of vesicle clusters, each correlating with one slope of the ATP expenses and efficiency plots. Group 1 (clear green) contains most peripheral clusters, which display the highest thermodynamic efficiency values. As seen Figure 12B, such clusters are immersed between both layers of endoplasmic reticulum and are the smaller, presumably for their contribution to constitutive release. The clusters in Group II (dark green) are embedded within the second layer of endoplasmic reticulum. Their transport velocities and efficiencies are smaller than those of Group I. The clusters in Group III (brown) rest in the borders of the actin cortex. Such large clusters move with high velocity and reach thermodynamic efficiencies above $1 \%$ presumably because they are propelled by both types of motors. The clusters in Group IV 
(red) are large and have not yet entered the actin cortex. Their velocities are smaller than those in Group III presumably for being carried purely by tubulin kinesin transport.50

It is to be noted that the $6.4 \%$ largest thermodynamic efficiencies in Figure 12 are only one third of the $\sim 20 \%$ efficiency of combustion motors of modern cars running on highways and one half the efficiency of the calcium ATPase.58 Therefore, modulating the workings of the nervous system occurs at a high energy cost, paradoxically due to the sophisticated and highly regulated machinery that couples electrical activity to exocytosis.
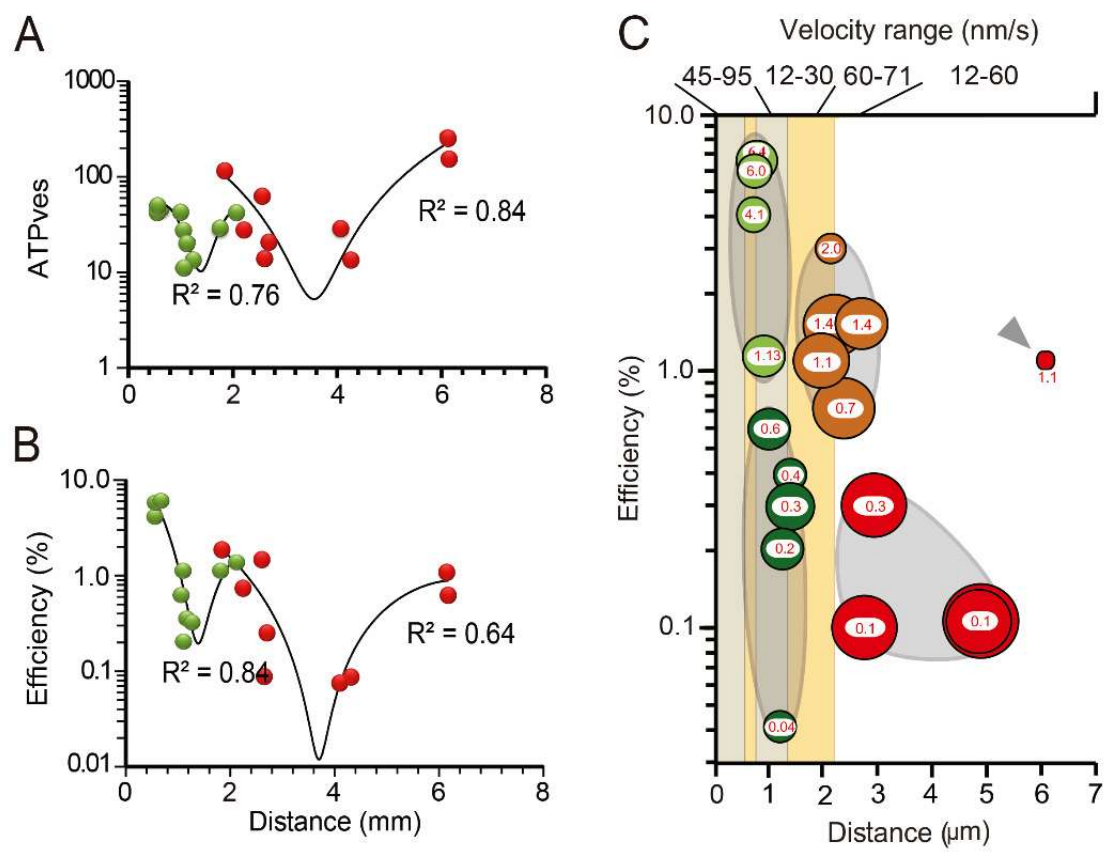

Figure 12. Structural and biophysical correlations of the thermodynamic efficiency of the ATP hydrolysis during vesicle transport. A. ATP expenses (top) and thermodynamic efficiency (bottom) of the transport depend on the travelling distance of vesicle clusters. Distances were calculated from model fittings to the exocytosis kinetics in combination to electron microscopy. B) Vesicle clusters are grouped according to their efficiency, size, distance and velocity. The thermodynamic efficiency of somatic exocytosis correlated with the thickness of the actin cortex (pale orange) and with the location of both layers of endoplasmic reticulum (gray bars). The cluster diameters were calculated from the number of vesicles in each cluster. The red numbers are the thermodynamic efficiency (\%); The black numbers are the transport velocity. Endoplasmic reticulum adjacent to the plasma membrane (er1) and $\sim 1 \mu \mathrm{m}$ inside (er2) are represented as grey bars. The number of vesicles decreases as the clusters approach the plasma membrane. The efficiency of the peripheral clusters decreased as the travelling distance increased. A is from reference 19; B and C are from reference 50 . 
Funding: This research was funded by a DGAPA-UNAM grant IN200914 and a CONACYT grant 130031 and by a Human Frontiers Science Program grants to FFDM.

Institutional Review Board Statement: Experiments described in this review were conducted according to the guidelines of the Declaration of Helsinki, and approved by the Institutional Ethics Committee of the Instituto de Fisiología Celular, Universidad Nacional Autónoma de México.

Data Availability Statement: Data presented in this review have been published as described along the text.

Conflicts of Interest: The author of this article declares no conflict of interest.

\section{References}

1. Huang LY, Neher E. Ca(2+)-dependent exocytosis in the somata of dorsal root ganglion neurons. Neuron. 1996. 17(1):13545.

2. Jaffe EH, Marty A, Schulte A, Chow RH. Extrasynaptic vesicular transmitter release from the somata of substantia nigra neurons in rat midbrain slices. J Neurosci. 1998. 18(10):3548-53.

3. Puopolo M, Hochstetler SE, Gustincich S, Wightman RM, Raviola E. Extrasynaptic release of dopamine in a retinal neuron: activity dependence and transmitter modulation. Neuron. 2001. 30(1):211-25.

4. Kaushalya SK, Desai R, Arumugam S, Ghosh H, Balaji J, Maiti S. Three-photon microscopy shows that somatic release can be a quantitatively significant component of serotonergic neurotransmission in the mammalian brain. J Neurosci Res. 2008. 86(15):3469-80.

5. Huang HP, Zhu FP, Chen XW, Xu ZQ, Zhang CX, Zhou Z. Physiology of quantal norepinephrine release from somatodendritic sites of neurons in locus coeruleus. Front Mol Neurosci. 2012; 5:29.

6. Trueta C, De-Miguel FF. Extrasynaptic exocytosis and its mechanisms: a source of molecules mediating volume transmission in the nervous system. Front Physiol. 2012. 3:319.

7. Borroto-Escuela DO, Perez De La Mora M, Manger P, Narváez M, Beggiato S, Crespo-Ramírez M, Navarro G, Wydra K, Díaz-Cabiale Z, Rivera A, Ferraro L, Tanganelli S, Filip M, Franco R, Fuxe K. Brain Dopamine Transmission in Health and Parkinson's Disease: Modulation of Synaptic Transmission and Plasticity Through Volume Transmission and Dopamine Heteroreceptors. Front Synaptic Neurosci. 2018 10:20.

8. Newman EA. Glial cell regulation of neuronal activity and blood flow in the retina by release of gliotransmitters. Philos Trans R Soc Lond B Biol Sci. 2015. 370(1672): 20140195.

9. Igelhorst BA, Niederkinkhaus V, Karus C, Lange MD, Dietzel ID. Regulation of neuronal excitability by release of proteins from glial cells. Philos Trans R Soc Lond B Biol Sci. 2015. 370(1672):20140194.

10. Kravitz EA. Hormonal control of behavior: amines and the biasing of behavioral output in lobsters. Science. 1988. 241(4874):1775-81.

11. Hirasawa H, Contini M, Raviola E. Extrasynaptic release of GABA and dopamine by retinal dopaminergic neurons. Philos Trans R Soc Lond B Biol Sci. 2015. 370(1672): 20140186.

12. Ludwig M, Apps D, Menzies J, Patel JC, Rice ME. Dendritic Release of Neurotransmitters. Compr Physiol. 2016. 7(1):235252.

13. Quentin E, Belmer A, Maroteaux L. Somato-Dendritic Regulation of Raphe Serotonin Neurons; A Key to Antidepressant Action. Front Neurosci. 2018. 12:982.

14. Hökfelt T, Barde S, Xu ZD, Kuteeva E, Rüegg J, Le Maitre E, Risling M, Kehr J, Ihnatko R, Theodorsson E, Palkovits M, Deakin W, Bagdy G, Juhasz G, Prud'homme HJ, Mechawar N, Diaz-Heijtz R, Ögren SO. Neuropeptide and Small Transmitter Coexistence: Fundamental Studies and Relevance to Mental Illness. Front Neural Circuits. 2018.12:106.

15. Delgado-Lezama R, Bravo-Hernández M, Franco-Enzástiga Ú, De la Luz-Cuellar YE, Alvarado-Cervantes NS, Raya-Tafolla G, Martínez-Zaldivar LA, Vargas-Parada A, Rodríguez-Palma EJ, Vidal-Cantú GC, Guzmán-Priego CG, Torres-López JE, 
Murbartián J, Felix R, Granados-Soto V. The role of spinal cord extrasynaptic $\alpha 5$ GABAA receptors in chronic pain. Physiol Rep. 2021. 16:e14984.

16. De-Miguel FF, Leon-Pinzon C, Torres-Platas SG, Del-Pozo V, Hernández-Mendoza GA, Aguirre-Olivas D, Méndez B, Moore S, Sánchez-Sugía C, García-Aguilera MA, Martínez-Valencia A, Ramírez-Santiago G, Rubí JM. Extrasynaptic Communication. Front Mol Neurosci. 2021 14:638858.

17. Grinevich V, Ludwig M. The multiple faces of the oxytocin and vasopressin systems in the brain. J Neuroendocrinol. 2021. 33(11):e13004.

18. Tobin VA, Ludwig M. The role of the actin cytoskeleton in oxytocin and vasopressin release from rat supraoptic nucleus neurons. J Physiol. 2007 582(Pt 3):1337-48.

19. De-Miguel FF, Santamaría-Holek I, Noguez P, Bustos C, Hernández-Lemus E, Rubí JM. Biophysics of active vesicle transport, an intermediate step that couples excitation and exocytosis of serotonin in the neuronal soma. PLoS One. 2012. 7(10):e45454.

20. De-Miguel FF, Leon-Pinzon C, Noguez P, Mendez B. Serotonin release from the neuronal cell body and its long-lasting effects on the nervous system. Philos Trans R Soc Lond B Biol Sci. 2015. 370(1672): 20140196.

21. Ma PM, Beltz BS, Kravitz EA. Serotonin-containing neurons in lobsters: their role as gain-setters in postural control mechanisms. J Neurophysiol. 1992. 68(1):36-54.

22. García-Pérez E, Vargas-Caballero M, Velazquez-Ulloa N, Minzoni A, De-Miguel FF. Synaptic integration in electrically coupled neurons. Biophys J. 2004. 86(1 Pt 1):646-55.

23. Aghajanian GK, Foote WE, Sheard MH. Lysergic acid diethylamide: sensitive neuronal units in the midbrain raphe. Science. 1968. 161(3842):706-8.

24. Mosko SS, Jacobs BL. Midbrain raphe neurons: spontaneous activity and response to light. Physiol Behav. 1974. 13(4):58993.

25. Trueta C, Sánchez-Armass S, Morales MA, De-Miguel FF. Calcium-induced calcium release contributes to somatic secretion of serotonin in leech Retzius neurons. J Neurobiol. 2004. 61(3):309-16.

26. Trueta C, Kuffler DP, De-Miguel FF. Cycling of dense core vesicles involved in somatic exocytosis of serotonin by leech neurons. Front Physiol. 2012. 3:175.

27. Del-Pozo, V. Mendez B. and De-Miguel FF. Calcium-induced mitochondrial ATP synthesis mediates vesicle transport for somatic exocytosis of serotonin. In preparation for submission.

28. Trueta C, Méndez B, De-Miguel FF. Somatic exocytosis of serotonin mediated by L-type calcium channels in cultured leech neurones. J Physiol. 2003. 547(Pt 2):405-16.

29. Hörner M, Weiger WA, Edwards DH, Kravitz EA. Excitation of identified serotonergic neurons by escape command neurons in lobsters. J Exp Biol. 1997. 200(Pt 14):2017-33.

30. Dreifuss JJ, Kalnins I, Kelly JS, Ruf KB. Action potentials and release of neurohypophysial hormones in vitro. J Physiol. 1971. 215(3):805-17.

31. Leon-Pinzon C, Cercós MG, Noguez P, Trueta C, De-Miguel FF. Exocytosis of serotonin from the neuronal soma is sustained by a serotonin and calcium-dependent feedback loop. Front Cell Neurosci. 2014. 8:169.

32. Fu XW, Nurse CA, Wong V, Cutz E. Hypoxia-induced secretion of serotonin from intact pulmonary neuroepithelial bodies in neonatal rabbit. J Physiol. 2002. 539(Pt 2):503-10.

33. Simmons ML, Terman GW, Gibbs SM, Chavkin C. L-type calcium channels mediate dynorphin neuropeptide release from dendrites but not axons of hippocampal granule cells. Neuron. 1995. 14:1265-1272. 
34. Shibuya I, Noguchi J, Tanaka K, Harayama N, Inoue U, Kabashima N, Ueta Y, Hattori Y, Yamashita H. PACAP increases the cytosolic $\mathrm{Ca} 2+$ concentration and stimulates somatodendritic vasopressin release in rat supraoptic neurons. J Neuroendocrinol. 1998. 10:31-42.

35. de Kock CP, Burnashev N, Lodder JC, Mansvelder HD, Brussaard AB. NMDA receptors induce somatodendritic secretion in hypothalamic neurones of lactating female rats. J Physiol. 2004 561:53-64.

36. de Kock CP, Cornelisse LN, Burnashev N, Lodder JC, Timmerman AJ, Couey JJ, Mansvelder HD, Brussaard AB. NMDA receptors trigger neurosecretion of 5-HT within dorsal raphe nucleus of the rat in the absence of action potential firing. J Physiol. 2006. 577:891-905.

37. Fernandez de Miguel, F, Cooper R, Adams WB. Synaptogenesis and calcium current distribution in cultured leech cells. Proc. R. Soc. Lond. B. 1992. 247, 215-221.

38. Patel JC, Witkovsky P, Avshalumov MV, Rice ME. Mobilization of calcium from intracellular stores facilitates somatodendritic dopamine release. J Neurosci. 2009. 29(20):6568-79.

39. Ludwig M, Sabatier N, Bull PM, Landgraf R, Dayanithi G, Leng G. Intracellular calcium stores regulate activity-dependent neuropeptide release from dendrites. Nature. 2002. 418(6893):85-9.

40. Wotjak CT, Ludwig M, Landgraf R. Vasopressin facilitates its own release within the rat supraoptic nucleus in vivo. Neuroreport. 1994. 5(10):1181-4.

41. Bao L, Jin SX, Zhang C, Wang LH, Xu ZZ, Zhang FX, Wang LC, Ning FS, Cai HJ, Guan JS, Xiao HS, Xu ZQ, He C, Hökfelt $\mathrm{T}$, Zhou Z, Zhang X. Activation of delta opioid receptors induces receptor insertion and neuropeptide secretion. Neuron. 2003. 9;37(1):121-33.

42. Harlow ML, Ress D, Stoschek A, Marshall RM, McMahan UJ. The architecture of active zone material at the frog's neuromuscular junction. Nature. 2001. 409(6819):479-84.

43. Neher E, Sakaba T. Multiple roles of calcium ions in the regulation of neurotransmitter release. Neuron. 2008. 59(6):861-72.

44. Nagwaney S, Harlow ML, Jung JH, Szule JA, Ress D, Xu J, Marshall RM, McMahan UJ. Macromolecular connections of active zone material to docked synaptic vesicles and presynaptic membrane at neuromuscular junctions of mouse. J Comp Neurol. 2009. 513(5):457-68.

45. Szule JA, Harlow ML, Jung JH, De-Miguel FF, Marshall RM, McMahan UJ. Regulation of synaptic vesicle docking by different classes of macromolecules in active zone material. PLoS One. 2012. 7(3):e33333.

46. Südhof TC. Neurotransmitter release: the last millisecond in the life of a synaptic vesicle. Neuron. 2013. 80(3):675-90.

47. Huang LY, Neher E. Ca(2+)-dependent exocytosis in the somata of dorsal root ganglion neurons. Neuron. 1996. 17(1):13545.

48. Witkovsky P, Patel JC, Lee CR, Rice ME. Immunocytochemical identification of proteins involved in dopamine release from the somatodendritic compartment of nigral dopaminergic neurons. Neuroscience. 2009. 164(2):488-96.

49. Mendez JA, Bourque MJ, Fasano C, Kortleven C, Trudeau LE. Somatodendritic dopamine release requires synaptotagmin 4 and 7 and the participation of voltage-gated calcium channels. J Biol Chem. 2011. 286(27):23928-37.

50. Noguez P, Rubí JM, De-Miguel FF. Thermodynamic Efficiency of Somatic Exocytosis of Serotonin. Front Physiol. 2019. 10:473.

51. Vitale ML, Seward EP, Trifaró JM. Chromaffin cell cortical actin network dynamics control the size of the release-ready vesicle pool and the initial rate of exocytosis. Neuron. 1995 14(2):353-63.

52. Oheim M, Stühmer W. Tracking chromaffin granules on their way through the actin cortex. Eur Biophys J. 2000. 29(2):6789.

53. Wang YF, Hatton GI. Mechanisms underlying oxytocin-induced excitation of supraoptic neurons: prostaglandin mediation of actin polymerization. J Neurophysiol. 2006. 95(6):3933-47. 
54. Tobin VA, Ludwig M. The role of the actin cytoskeleton in oxytocin and vasopressin release from rat supraoptic nucleus neurons. J Physiol. 2007. 1;582(Pt 3):1337-48.

55. Torregrosa-Hetland CJ, Villanueva J, Giner D, Lopez-Font I, Nadal A, Quesada I, Viniegra S, Expósito-Romero G, Gil A, Gonzalez-Velez V, Segura J, Gutiérrez LM. The F-actin cortical network is a major factor influencing the organization of the secretory machinery in chromaffin cells. J Cell Sci. 2011. 124(Pt 5):727-34.

56. Trifaró JM, Lejen T, Rosé SD, Pene TD, Barkar ND, Seward EP. Pathways that control cortical F-actin dynamics during secretion. Neurochem Res. 2002. 27(11):1371-85.

57. Villanueva J, Gimenez-Molina Y, Viniegra S, Gutiérrez LM. F-actin cytoskeleton and the fate of organelles in chromaffin cells. J Neurochem. 2016. 137(6):860-6.

58. Lervik A, Bresme F, Kjelstrup S, Rubí JM. On the thermodynamic efficiency of $\mathrm{Ca}^{2+}$-ATPase molecular machines. Biophys J. 2012. 103(6):1218-26. 